\title{
REFLEXÕES DO PÓS-NACIONALISMO MUSICAL: UMA ABORDAGEM HISTÓRICA E COMPOSICIONAL SOBRE OS FLAUTISTAS ALTAMIRO CARRILHO, EGILDO VIEIRA E HERMETO PASCOAL
}

\author{
Reflections of musical post-nationalism: a historical and compositional \\ approach on the flutists Altamiro Carrilho, Egildo Vieira and Hermeto Pascoal \\ Reflexiones sobre la música del post-nacionalismo: una aproximación histórica y \\ compositiva a los flautista Altamiro Carrilho, Egildo Vieira e Hermeto Pascoal \\ Leonardo Araujo da Silva ${ }^{1}$ \\ Rucker Bezerra de Queiroz ${ }^{1}$
}

\section{Resumo:}

O trabalho faz uma análise das obras de Altamiro Carrilho (1924-2012), Egildo Vieira do Nascimento (1947-2015) e Hermeto Pascoal (1936). Estudo motivado por discussões sobre interpretação de fragmentos melódicos de ritmos de danças brasileiras escritas no Método Ilustrado para Flauta de Woltzenlogel (1984). Além disso, apresenta uma síntese histórica do instrumento no Brasil, que discute a construção de identidade musical propondo para os flautistas uma reflexão da prática interpretativa da música popular brasileira com referência nas perspectivas do musicólogo Mário de Andrade (1893-1945) sobre a criação de um repertorio nacional; da expressão musical do flautista e compositor Alfredo da Rocha Vianna o "Pixinguinha" (1892-1975); da evolução da flauta e seus aspectos técnicos (RONAI, 2008); do panorama da história da flauta na música brasileira (DIAS, 1996); dos estilos musicais do século XVIII (DIAS, 1985); do folclore na música erudita (DALDENGAN; COSTA, 2014); da paisagem sonora (SCHAFFER, 1997); da gaita e seus reflexos na composições brasileiras (ANJOS, 2013); da história da música nacional (MARIZ, 1983); do choro no contexto social (DINIZ, 2003), da educação popular (BARREIRAS, 1980); da análise harmónica (CHEDIAK, 2009); da teoria musical (MED, 1996) e do gênero musical (TINHORÂO, 2013).

Palavras-chave: Flautista brasileiro; Flauta-transversal; Música popular; Pós-nacionalismo musical.

\begin{abstract}
:
The work analyzes the works of Altamiro Carrilho (1924-2012), Egildo Vieira do Nascimento (1947-2015) and Hermeto Pascoal (1936). This study was motivated by discussions on the interpretation of melodic fragments of Brazilian dance rhythms written in the Woltzenlogel Illustrated Method for Flute (1984). This work presents a historical synthesis about the flute instrument in Brazil, and discusses the construction of musical identity, proposing to the flutists a reflection on the interpretative practice of Brazilian popular music based on the perspectives of the musicologist Mário de Andrade (1893-1945) on the creation of a national repertoire; the musical expression of the flutist and composer Alfredo da Rocha Vianna "Pixinguinha" (1892-1975); on the evolution of the flute and its technical
\end{abstract}

${ }^{1}$ Universidade Federal do Rio Grande do Norte - UFRN 
aspects (RONAI, 2008); on the historical panorama of the flute in Brazilian music (DIAS, 1996); on the musical styles of the 18th century (DIAS, 1985); on the folklore in classical music (DALDENGAN; COSTA, 2014); on the soundscape (SCHAFFER, 1997); the harmonica and its reflexes in Brazilian compositions (ANJOS, 2013); the history of the national musical (MARIZ, 1983); choro in the social context (DINIZ, 2003) and popular education (BARREIRAS, 1980); musical theory (MED, 1996); harmonic analysis (CHEDIAK, 2009) and musical genre (TINHORÂO, 2013).

Keywords: Brazilian flutist; Transverse flute; Popular music; Musical post-nationalism

\section{Resumen}

La obra hace un análisis de las obras de Altamiro Carrilho (1924-2012), Egildo Vieira do Nascimento (19472015) y Hermeto Pascoal (1936). Estudio motivado por discusiones sobre la interpretación de fragmentos melódicos de ritmos de danza brasileña escritos en el Método Ilustrado para Flauta de Woltzenlogel (1984). Además, presenta una síntesis histórica del instrumento en Brasil, en la que se discute la construcción de una identidad musical proponiendo a los flautistas una reflexión sobre la práctica interpretativa de la música popular brasileña con referencia a las perspectivas del musicólogo Mário de Andrade (1893-1945) sobre la creación de un repertorio nacional; la expresión musical del flautista y compositor Alfredo da Rocha Vianna la "Pixinguinha" (18921975); la evolución de la flauta y sus aspectos técnicos (RONAI, 2008); el panorama de la historia de la flauta en la música brasileña (DIAS, 1996); los estilos musicales del siglo XVIII (DIAS, 1985); el folclore en la música clásica (DALDENGAN; COSTA, 2014); el paisaje sonoro (SCHAFFER, 1997); la armónica y sus reflexiones sobre las composiciones brasileñas (ANJOS, 2013); la historia del musical nacional (MARIZ, 1983); el choro en el contexto social (DINIZ, 2003); la educación popular (BARREIRAS, 1980); la teoría musical (MED, 1996); el análisis armónico (CHEDIAK, 2009) y el género musical (TINHORÂO, 2013).

Palabras clave: Laboratorio de desempeño; Flauta transversal; Música popular

\section{Introdução}

O foco central deste trabalho são os compositores Altamiro Carrilho, Hermeto Pascoal e Egildo Vieira. São músicos que exploraram as sonoridades de suas respectivas regiões e que compuseram um repertório, através do marco sonoro dos folguedos e das manifestações populares, para linguagem interpretativa da flauta-transversal na música popular. Ritmos, melodias e expressões do pós-nacionalismo musical dando grandes contribuições, especialmente, ao repertório da flauta transversal brasileira.

A seleção das quatros obras para flauta transversal ocorreu pelo motivo das composições serem frutos de inspiração advinda das situações e sentimentos do cotidiano de um povo ou aquelas que transmitiram uma paisagem sonora de acordo com elementos encontrados em uma região. Vale lembrar que:

\footnotetext{
A paisagem sonora é qualquer campo de estudo acústico. Podemos referir-nos a uma composição musical, a um programa de rádio ou mesmo a um ambiente acústico com paisagens sonoras. Todavia, formular uma impressão exata de uma paisagem sonora é mais difícil do que a de uma paisagem visual (SCHAFER, 1997, p. 23).
}

O laboratório da performance promove a construção colaborativa de conhecimentos, através das análises e críticas da produção musical, do fazer artístico até o processo de construção da interpretação musical. Selecionando referências textuais apropriadas para os objetivos propostos no plano de atuação, buscando sempre a renovação crítica e atuante das ideias acerca do processo de aprendizagem da performance.

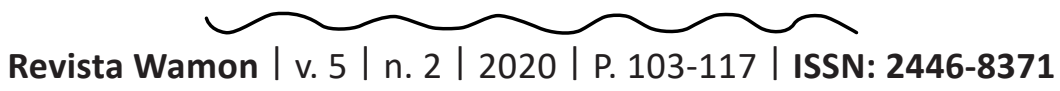


Sendo assim, aplicamos na metodologia para este estudo a pesquisa bibliográfica, pesquisa documental sonora - que inclui gravações em áudio e vídeo. Foram realizadas escutas dos fonogramas, buscas dos elementos de tradição oral, pesquisas dos ritmos e da história dos movimentos Nacionalista e Pós-nacionalista.

Entrevistas semiestruturadas com Celso Woltzenlogel $(1940)^{2}$, mestre Sebastião Biano $(1919)^{3} \mathrm{e}$ Maestro Ademir Araújo (1942) ${ }^{4}$ sobre interpretação musical. Com "Zé Alfaiate" (1933-2016) sobre a tradição da agremiação popular, com Antônio Madureira $(1949)^{6}$ sobre a formação do quinteto Armorial' com Jarbas Maciel (1933-2019) ${ }^{8}$ sobre a formação da orquestra Armorial, grupos que pertenceram ao Movimento Armorial criado por Ariano Suassuna (1927-2014)9.

O homem é uma dimensão original de existência no mundo. Ele está em seu mundo (é uma corporeidade em seu meio físico), mas não se esgota nele (é uma transcendência dessa corporeidade e desse meio físico). O seu modo próprio de colocar-se em seu mundo é a oposição com que se define frente a um mundo dado (dimensão de existência em que o animal se esgota em seu mundo) que o homem transforma em realidade construída para si ao recriar um mundo de natureza (coisas) em um mundo de cultura objetos, valores, relações para o homem (BARREIRAS, 1980.p. 51).

A flauta transversal, apesar de ser considerada um instrumento versátil para muitos, ainda é pouco explorada no repertório nacional. A formação dos flautistas nos cursos médios, técnicos e superiores das instituições de ensino de música no Brasil, em sua grande maioria, enfatizam a música europeia, como se somente existissem as orquestras e bandas sinfônicas, as quais, geralmente, utilizam-se desse repertório.

Entretanto, estes grupos artísticos não devem ser os únicos espaços para os flautistas tocarem, pois a desvalorização do conhecimento popular contribui para o esquecimento das diversidades e características composicionais da música brasileira. Suas particularidades e sutilezas exigem um bom nível técnico-interpretativo, os quais requerem vivência do flautista na música regional e com a cultura nacional.

Historicamente os flautistas brasileiros sempre estiveram ligados as manifestações musicais dos mais variados campos. Formados em bandas, rodas de choro, escolas de música ou autodidatas, assimilam influencias com extrema sensibilidade e delas se valem para naturalmente fixar uma expressão tipicamente nacional, com inúmeras formas do entendimento do discurso musical quando se trata de assimilar um discurso popular isto é aprender a tocar choro, samba, baião, frevo e tantos outros gêneros que compõem o legado musical brasileiro isso se dá basicamente de uma maneira informal está informalidade se resume principalmente no chamado aprendizado de ouvido, ou, seja depende de aguçada percepção auditiva, resultando numa experiência intuitiva predominante sobretudo entre os instrumentistas de acompanhamento harmônico no caso do choro os violonista e cavaquinhista ou mesmo o piano e acordeon (DIAS, 1996.p. 5)

\footnotetext{
${ }^{2}$ Flautista brasileiro nascido em Piracicaba, Rio de janeiro.

${ }^{3}$ Pifeiro integrante da Banda de Pífano de Caruaru

${ }^{4}$ Maestro e compositor pernambucano.

${ }^{5}$ Fundador do Cabocolinho Sete Flechas

${ }^{6}$ Violonista e compositor de movimento Armorial.

${ }^{7}$ Grupo camerístico criado por Ariano Suassuna para interpretar musica das tradições populares do estado

${ }^{8}$ Violista, compositor e criador da orquestra Armorial

${ }^{9}$ Movimento Armorial inciativa de Ariano Suassuna, cujo objetivo seria criar uma arte erudita a partir de elementos da cultura popular do nordeste brasileiro
} 
As principais modificações sofridas na flauta transversal surgiram com os tratados de Jacques-Martin Hoteterre (1674 - 1763), músico, compositor e construtor de instrumentos do século XVII, e Joaquim Quantz (1697 - 1773) compositor e construtor século XVIII. Foram ajustes na acústica e mecanismos do instrumento, recursos modificados para obter qualidade na sonoridade e amplitude timbrística do instrumento, principalmente para que fossem inseridas na massa sonora das orquestras sinfônicas do século XI - grupo artístico com aproximadamente 60 instrumentistas tocando simultaneamente.

Além disso, o sistema Bohm de Theobald Böhm (1794 - 1881), construtor do século XIX, apresentou novas mudanças com mais recursos que facilitaram a afinação no encaixe das partes da flauta (cabeça, corpo e pé) e entre as duas chaves do registro grave, um rolete para facilitar a execução dando flexibilidade para o "dedo mínimo" nesta região do instrumento.

No Brasil, a primeira flauta transversal de prata veio através de um músico Belga trazido pelo Corte Real de Dom Pedro II.

\begin{abstract}
As pesquisas de Theobald Boehm tinha fixado em 1832 os padrões de flauta transversal de prata (sistema Boehm), que Reichert foi um dos primeiros a introduzir no Brasil. Esse novo modelo do instrumento não foi adotado sem discussões e polemicas; houve até uma celebre disputa entre Callado e o próprio Reichert a respeito das qualidades respectivas da flauta de prata e da flauta de Ébano, e ... dos próprios flautistas - disputa amigável e proveitosa onde foram realçadas as qualidades de cada um. (DIAS, 1990. p. 16)
\end{abstract}

Relatos indicam que foi por André Mathieu Reichert (1830-1880), flautista da Corte Real, que tornou-se ao chegar no Brasil composições de polcas, lundus, valsas e estudos, além da produção de métodos com suas composições, exercícios técnicos e estudos diários utilizados atualmente nos programas de música dos conservatórios e das universidades. Em seguida havia também Antônio Joaquim da Silva Callado (1848-1880), flautista e compositor de modinhas e polcas. Callado foi considerado músico da primeira geração de chorões e compôs o Flor Amorosa, choro genuinamente brasileiro.

Quanto as peças, hoje escuto muito delas com interesse cada vez maior. Dentro da linguagem da época com seus modismos elas apresentam uma grande originalidade melódica formal e uma riqueza de recursos técnicos que com certeza influenciaram o próprio choro virtuosístico depois de Callado e Reichert. Reichert trouxe ao Brasil sua personalidade musical e enriqueceu a linguagem instrumental (Dias, 1990. p. 22).

Patápio Silva (1880-1907) foi um virtuose brasileiro, compositor de valsas, serenatas, polcas do século XIX, aluno do Duque Estrada do Conservatório Nacional de Música do Rio de Janeiro. Patápio Silva gravou um repertório erudito em suas gravações pela casa Edson. Alfredo da Rocha Viana filho (18971973), o "Pixinguinha" herdou a musicalidade dos chorões do século XIX, além da tradição afro-brasileira, tornando-se o melhor compositor e intérprete de choro de todos os tempos.

Um dos grandes gênios da música do século XX, "Pixinguinha" criou uma linguagem interpretativa com o seu estilo autêntico de tocar choro na flauta, gênero musical efervescente na época, tanto que despertou admiração do musicólogo Mario de Andrade e do compositor Villa Lobos. Maestro e arranjador, "Pixinguinha" adquiriu conhecimento através de suas experiências e vivência com seu pai que realizava rodas de choros em casa e com professor Irineu de Almeida, "Irineu Batina", músico que frequentava a casa responsável pelos ensinamentos de contrapontos no gênero.

"Pixinguinha" compôs diversos choros, os mais conhecidos são "Carinhoso", "Um a Zero", "Sofres porque queres" e "Lamento". Ele também participou de grandes grupos naquela época - os quais fizeram tur- 
nê nacional e internacional - tais como Oito Batutas, o qual era composto por Pixinguinha, Donga, China, Nelson Alves, José Alves de Lima, José Monteiro, Caninhas, Josué de Barros e o baterista. Em 1954, Pixinguinha formou duo com Benedito Lacerda de flauta e saxofone que resultou na gravação de um álbum.

O mais importante nesses fonogramas, porém é que eles mostram um estreante deveras especial, de característica inovadoras. Isso é ressaltado pelo músico Henrique Cazes em seu livro Choro: do quintal ao teatro municipal: o sopro da flauta de Pixinguinha [...] não se parecia nem um pouco com o dos flautista acadêmicos da época. Era muito mais rítmico, sem vibrato, e conforme nos explica a tese a expressão da flauta popular brasileira de Andrea Ernest Dias, um som gerado com muito ar e golpes energéticos" (SEVERIANO, 2017. p. 82).

Contribuímos para o não esquecimento das modificações que esse instrumento sofreu a partir do século XVI, sobretudo no século XX que através de grandes gênios da música popular brasileira e outros elementos que trouxeram a linguagem e sonoridades dos instrumentos rústicos como o "Pífano do Zabumba10", orquestra típica do nordeste e a gaita ${ }^{11}$ do cabocolinho para composições.

A gaita pode ter reminiscências das antigas flautas indígenas como o próprio contexto de atuação sugere, mas como se sabe, dentro do processo dinâmico de formação da cultura brasileira no decorrer de sua história, com os elementos étnicos se influenciando e se amalgamando continuamente, é difícil de acreditar que seus construtores-artesãos, índios, negros ou mestiços, tenham se isolado de qualquer interferência externa. Em nossa opinião, trata-se de um instrumento produzido pelas mãos do mestiço brasileiro (mulato, caboclo ou cafuzo) possivelmente em meados do século XVIII que, sob os efeitos da civilização, soube sabiamente aproveitar inicialmente os recursos e os objetos disponíveis à sua volta como o bambu, a taboca ou a taquara, e mais recentemente os canos de alumínio ou PVC, para construir criativamente um instrumento simples, porém versátil e de acordo com os padrões de seu contexto cultural (ANJOS 2013, p. 59).

\section{Referencial Teórico}

\section{Cesar Guerra-Peixe - Inúbia do Cabocolinho}

A inúbia do cabocolinho de 1956, que o autor considera uma peça orquestral para pequena orquestra com flautim solista, também mereceu, em abril de 1971, três versões: piano solo, violino e piano e flauta e piano. César Guerra-Peixe evoca o som agudo da "inúbia" (flauta de madeira usada nos grupos de "caboclinhos" de Pernambuco) e a agilidade de seus intérpretes. Trata-se de uma obra que vem interessando cada vez mais os intérpretes e o público.

Caboclinho ou cabocolinhos no plural é a uma tradição cuja transmissão se desenvolve, sobretudo, com base na oralidade. $\mathrm{O}$ termo designativo tem mais de um significado: é um tipo de agremiação popular e o nome do integrantes dessas agremiações; e a denominação dada a música e a dança às vezes focalizada individualmente: é também o nome da própria brincadeira e a totalidade dos participantes costuma chamá-los de cabocolinhos (SANTOS, 2009. p. 19).

\footnotetext{
${ }^{10}$ Bandas de pífanos denominadas por César Gerra-Peixe http://www.guerrapeixe.com/

${ }^{11}$ Organologia do instrumento aerofone, gaita de bisel instrumento melódico do caboclinho
} 


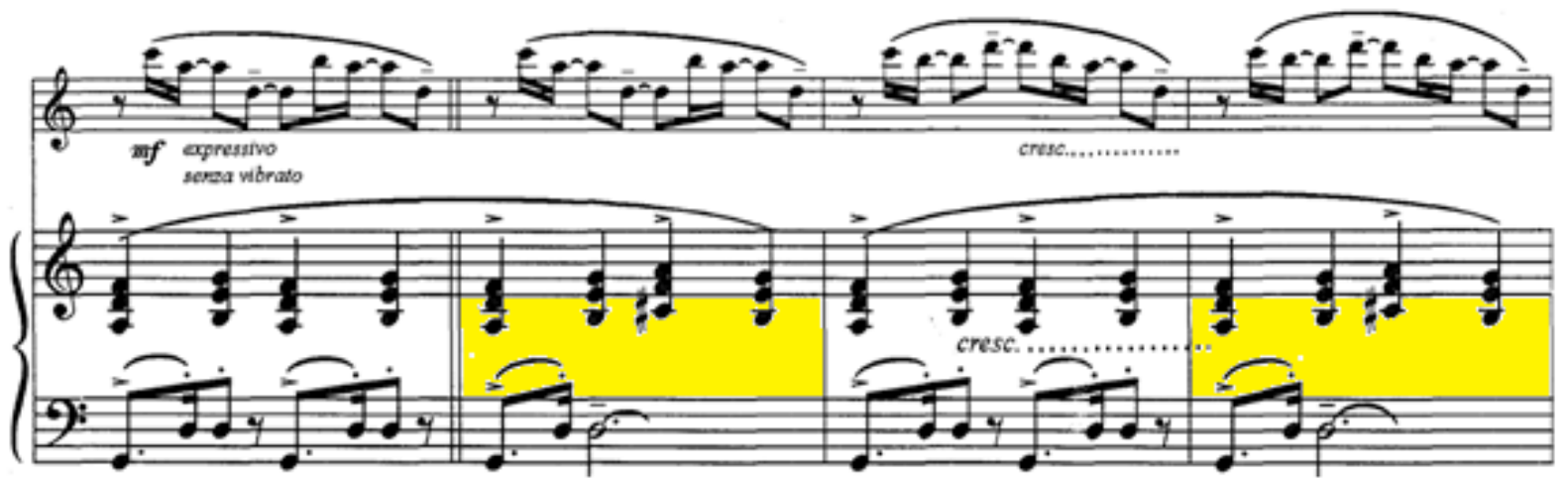

Figura 1 - Análise musical dos fragmentos melódicos da Inúbia do caboclinho 1956. Modo dórico 6a maior, intervalo que caracteriza o modo no terceiro acorde do segundo e quarto compasso

\section{Método Ilustrado para Flauta}

O Método ilustrado para flauta transversal foi a principal abordagem para esta pesquisa. A referida publicação foi editada em 1984 pelo autor Celso Woltzenlogel, o qual atribuiu às suas lições, melodias e ritmos característicos da música brasileira como samba, valsa, maracatu, frevo, choro, cantigas e toadas. As quais também estão expressas seus fragmentos de suas síncopes irregulares, regulares, acentuações, articulações e efeitos sonoros.

Método para flauta-transversal que aproxima-se da realidade da linguagem da música popular brasileira. Como recurso didático utiliza-se de composições, trazendo estudos técnicos-interpretativos encontrados nas composições de autores brasileiros. Material didático que direciona o flautista para realidade do mercado musical brasileiro associando à vivência, além do conhecimento sobre a teoria musical, da pratica de conjunto, da formação de repertório, da criatividade e da criação composicional.

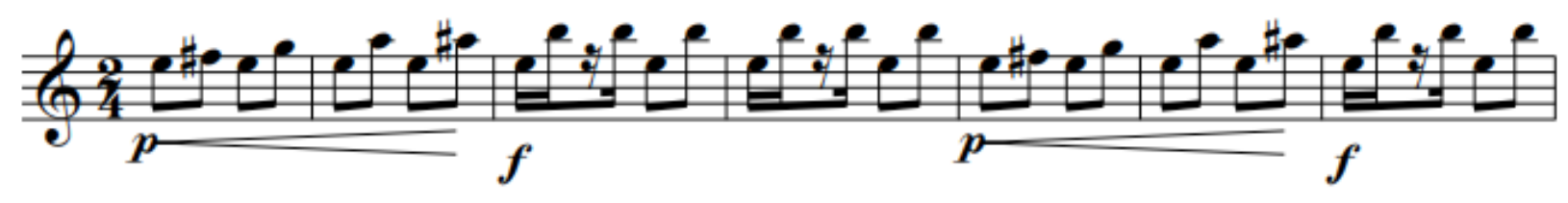

Figura 2 - Fragmento melódico do estudo de danças composto por Guerra-Peixe no capítulo em Três Flautas do Método Ilustrado. (WOLTZENLOGEL, 1984. p. 24)

O autor relata através de entrevista que o método foi pensado para facilitar a aprendizagem das técnicas para os flautistas iniciantes e autodidatas. Naquela época havia uma grande necessidade por um método genuinamente com concepções rítmicas e melódicas dentro da estética da música nacional.

[...] Depois que eu voltei de Paris um belo dia o Guerra-Peixe me falou: você não vai fazer um método para flautista, olha cuidado se você não fazer o Mario Mascarenhas vai escrever. Eu disse: olha "Guerra" eu tenho uma ideia melhor, uma grande ideia, mas não sou compositor. O Guerra-Peixe me disse: se preocupe com a parte técnica do método. Então, o Guerra-Peixe começou a escrever os estudos. Devido as minhas experiências nos estúdios, gravando música popular um dia fui gravar no lugar do Nicolino Cópia o "Copinha” e percebi que havia uma necessidade de escrever todas aquelas sincopes encontradas nas composições de música brasileira. Por isso que convidei alguns compositores para escreverem estudos sob sincopes, no método tem um capitulo somente de estudos de sincopes" (WOLTZENLOGEL, 2020). 


\section{Grandes nomes - Trajetórias e Obras}

Nascidos no século XX, estes músicos vivenciaram os períodos do nacionalismo ${ }^{12}$ e pós-nacionalismo, ou seja, a música nacionalista do Brasil tocada pelo seu grande expoente, o músico, compositor e professor Heitor Villa Lobos. Todos eles levaram adiante os questionamentos efetuados durante a "Semana da Arte Moderna ${ }^{13 "}$ em 1922 e as catalogações e pesquisas realizadas por Mário de Andrade em todo o país, contribuindo assim para o movimento que incitou os compositores a deixarem de seguir a forma europeia, destacaram as raízes culturais e descreveram o cotidiano social do povo brasileiro.

De acordo com o que foi dito, apresentaremos uma análise musical, histórica e biográfica contextualizada desde o principal precursor do Nacionalismo e respectivos compositores do movimento Pós-nacionalista bem como gerações de músicos advindos do mesmo segmento composicional.

\section{Heitor Villa Lobos (1887-1959)}

Heitor Villa Lobos nasceu no Rio de Janeiro no dia 05 de março de 1887. Sua iniciação na música foi possibilitada pelo pai, Raul Villa Lobos, que lhe ensinou a tocar violoncelo e clarineta e ministrou-lhe as primeiras lições teóricas em música. Já na infância, mesmo sendo forçado a ouvir estilos musicais europeus como Fuga e Sonatas, surgiram questionamentos sobre as formas composicionais da música de Bach e da música caipira do folclore brasileiro, pois ouvia nos rádios as modas caipiras e tocadores de pinhos.

Aos 11 anos, ao frequentar com seu pai a casa de Alberto Brandão onde se reuniam os cantadores e seresteiros, travou conhecimento da música nordestina. Villa Lobos conheceu de perto quase todos os aspectos do Brasil sonoro durante suas viagens por grande parte do país. A convivência prolongada com os "Chorões Cariocas" e o nacionalismo inato forneceram-lhe copiosos materiais para a criação de música autenticamente brasileira.

Visitou os estados do Espirito Santo, Bahia e Pernambuco e lá espantou-se com a riqueza folclórica, meteu-se nos bairros mais duvidosos de Salvador e do Recife em busca de aspectos curiosos do populário local; embrenhou-se nos sertões daqueles estados, temporadas em engenho e fazendas. A música dos cantadores, impostação (ou desimpostação) no cantar, a afinação de seus instrumentos primitivos, os aboios dos vaqueiros, os autos e danças dramáticas, os desafios, tudo isso se despertou o sentido de brasilidade que trazia no sangue (MARIZ, 1983, p.113).

Villa Lobos, por sua vez, cria uma linguagem musical que se tomaria modelo para os novos compositores. Depois de sua fase pós-romântica e impressionista, abraçou fortemente o nacionalismo a partir de 1917. Em algumas obras desta fase, o compositor reflete um forte sentimento de brasilidade, sem utilizar temas folclóricos. Em outras, no entanto, observa-se o aproveitamento literal ou transformado de temas folclóricos brasileiros. A partir daí cresce cada vez mais o interesse dos compositores em estudar o folclore brasileiro em vistas a uma melhor aplicação dentro da música erudita nacional (DALDEGAN, Valentina; COSTA, Raul. 2014, p.105).

Villa Lobos - principal expoente da primeira geração de compositores nacionalistas - em 1922 trouxe para academia musical sua obra choros n $2^{\circ}$ para flauta e clarineta, peça musical com elementos oriundos do "choro", formas contrapontísticas, ornamentos e andamentos. Dando continuidade a este período, Villa Lobos expandiu sua forma composicional estimulando e influenciando novos compositores.

\footnotetext{
${ }^{12}$ Nacionalismo musical música composta com influência da música folclórica nacional e gênero

${ }^{13}$ Semana da arte moderna constitui-se em debates fundamentais sob todos os aspectos artísticos: A atualização da inteligência artística brasileira e a estabilização duma consciência criadora nacional.
} 


\section{Mário Raul de Morais Andrade (1893-1945)}

Mário Raul de Moraes Andrade (São Paulo, 9 de outubro de 1893 - São Paulo, 25 de fevereiro de 1945) ou simplesmente Mario de Andrade, foi um dos pioneiros da poesia moderna brasileira com a publicação de seu livro Pauliceia Desvairada em 1922. Poeta, escritor, crítico literário, musicólogo e folclorista brasileiro, exerceu grande influência na literatura moderna brasileira e, como ensaísta e estudioso, foi pioneiro no campo da etnomusicologia, sendo que sua influência transcendeu as fronteiras do Brasil.

\section{César Guerra-Peixe (1914-1993)}

Cesar Guerra Peixe, o grande nome da primeira geração Pós-nacionalista, com excepcional experiência tanto na música erudita quanto na música popular, nasceu em Petrópolis, Rio de Janeiro, no dia 18 março de 1914. Em 1931 ingressou na Escola Nacional de Música do Rio de Janeiro onde estudou com Arnold Gouveia. No mesmo período, transferiu-se para capital e fez parte de orquestras de salão em confeitarias, bares, cafés e Orquestras Sinfônicas.

Em 1949, Guerra-Peixe visitou o Recife numa excursão, ficando impressionado com o folclore pernambucano. Nos anos seguintes, aceitou um contrato para orquestrador e compositor da "Rádio do Jornal do Commercio. A fim de estudar os aspectos do folclore nordestino, Guerra Peixe aceitou o emprego ${ }^{14}$.

\footnotetext{
[...] Guerra-Peixe aderiu tornou-se um folclorista veio aqui para pesquisar, Clóvis Pereira e eu éramos ajudando dele na pesquisa do Xangô, uma vez por mês a gente subia era uma Xangô autêntico uma coisa tão seria que pra gente subir tinha que alguém vir buscar. A gente amanhecia o dia lá anotando, Clóvis Pereira anotava as toadas e eu anotava os ritmos muito difícil, cada ritmo de lascar era o nome dele era o Bongar, não sei se era contemporâneo de dona Santa, mas era descendente um negro chamado Costa Velha. Ele trouxe toda essa mitologia negra e a passou isso pra cá, ele gravou dezenas e dezenas de ritmos de Xangô, começa por Exu, Xamar, Ijexá um nome estranho Guerra-Peixe ria achava graça (MACIEL, 2014).
}

Aprofundou-se colhendo temas, anotando ritmos, observando cada peça e reinventando conclusões publicadas em suas obras Maracatu do Recife. Aos treze anos de idade mudou-se para Niterói, período em que começou a frequentar programas de rádio. Neste mesmo período, conquistou o primeiro prêmio no programa "Calouros em desfile" apresentado por Ari Barroso.

\section{Altamiro Carrilho (1924-2012)}

Altamiro Aquino Carrilho, membro de família de músicos, nasceu na cidade de Santo Antônio de Pádua (RJ), em 21 de dezembro de 1924. Revelou seu talento musical muito cedo, aos 06 anos de idade, tocando na banda Lira de Arion, formada pelos seus parentes. Seu primeiro professor de flauta foi Joaquim Fernandes, um carteiro, músico amador, que entregava cartas em sua residência.

Autodidata, sua base técnica de flauta foi desenvolvida inicialmente a partir dos estudos dos métodos para flauta "Taffanel e Gaubert"15 que o tornaram um instrumentista de grande capacidade técnica, além da improvisação.

\footnotetext{
${ }^{14} \mathrm{http} / / /$ www.guerrapeixe.com/. Acesso em 07/11/2019.

${ }^{15}$ Taffanel \& Gauber. Alphonse Leduc: Paris, 1943.
} 
As questões vislumbradas na performance e no aprendizado da música estão relacionadas aos métodos utilizados para se ensinar um determinado tipo de instrumento e como isso pode afetar o interprete no ato da performance. Além disso, nos deparamos com os temas relacionados ao ensino das técnicas especificas para execução em cada estilo de acordo com a natureza de cada instrumento. Com referência a Altamiro Carrilho, de família de músicos teve contato com a música muito cedo já aos seis anos tocava flauta de bambu, também tocava tarol na Banda Lira de Árion, formada na maioria por seus parentes. A experiência com a banda proporcionou um contato importante com a música, sendo que o maestro que era seu tio, não admitia qualquer deslize durante os ensaios. Segundo Carrilho (2004), isto teria lhe dado um bom domínio do ritmo e uma capacidade de se adaptar à disciplina exigida nos estudos técnicos do instrumento (SARMENTO 2005 p. 11).

Destacou-se chamando atenção de artistas, o que o levou, em 1951, a participar de vários grupos da época como o Regional de Canhoto, o qual tinha grande respaldo. Além disso, Altamiro Carrilho, durante sua carreira profissional, sempre participou, de certa maneira, das gravações de álbuns como diretor musical, arranjador e solista. Altamiro compunha outros gêneros influenciado pelo samba do bairro do Estácio, mais conhecido pelo samba de asfalto, compôs choro samba e choro batucada, os interpretavam da sua maneira enfatizando/elevando a expressão idiomática e elementos do choro na flauta-transversal.

\section{Hermeto Pascoal (1936)}

Nascido em Olho d'Água em 22 de junho de 1936, porém criado em Lagoa da Canoa, na época município de Arapiraca no estado de Alagoas, Hermeto Pascoal, filho de Vergelina Eulália de Oliveira e Pascoal José da Costa, desde pequeno mostrava fascinação pelos sons da natureza. Quando criança a partir de um cano de mamona de “jerimum” (abóbora), fazia um pífano e ficava tocando para os passarinhos. Até o 8 baixos de seu pai, de sete para oito anos, ele resolveu experimentar e não parou mais.

Dessa forma passou a tocar com seu irmão mais velho, José Neto, em forrós e festas de casamento, revezando-se com ele nos oitos baixos e no pandeiro. Hermeto Pascoal, músico autodidata, destacou-se pela aptidão de multi-instrumentista além de compositor e arranjador. Mudou-se para Recife em 1950 e foi para a Rádio Tamandaré. De lá logo foi convidado, com a ajuda do Severino Dias de Oliveira "Sivuca" (sanfoneiro já de sucesso), para integrar a Rádio Jornal do Commercio.

Formou o trio "O Mundo Pegando Fogo", que pegou fogo mesmo já na primeira vez em que tocaram, pois, segundo Hermeto, ele e seu irmão estavam apenas começando a tocar sanfona, ou seja, eles só tocavam mesmo Oitos Baixos ${ }^{16}$ até então. Porém, por não querer tocar pandeiro e sim sanfona, foi mandado para a Rádio Difusora de Caruaru como refugo pelo diretor da Rádio Jornal do Commercio, o qual disse-lhe que "não dava para música".

Em 1969, a convite de Flora Purim e Airto Moreira, viajou para os Estados Unidos e gravou com eles dois LPs, atuando como compositor, arranjador e instrumentista. Nessa época conheceu Miles Davis e gravou com ele duas músicas suas: "Nem um talvez" e "Igrejinha”. De volta ao Brasil, gravou o LP "A música livre de Hermeto Pascoal", com seu primeiro grupo, em 1973.

O nome já reconhecido pelo talento, pela qualidade e por sua criatividade, tornou-se a atração de diversos eventos importantes, como o I Festival Internacional de Jazz / 1978 em São Paulo. No ano seguinte, participou do Festival de Montreux, na Suíça, quando foi editado o álbum duplo Hermeto Pascoal ao

\footnotetext{
${ }^{16}$ Acordeon menor com poucos recursos
} 
vivo e seguiu para Tóquio onde participou do Live under the sky. Lançou o Cérebro magnético em 1980 e multiplicou suas apresentações pela Europa. Apresenta-se no Brasil, em turnês pela Europa com cinco formações: Hermeto Pascoal e grupo, Hermeto Pascoal e Aline Morena, Hermeto Pascoal Solo, Hermeto Pascoal e Big Band, Hermeto Pascoal e Orquestra Sinfônica (VILLAÇA, 2007, p. 31).

\section{Egildo Vieira do Nascimento (1947-2015)}

Natural da cidade de Piranhas - AL, Egildo Vieira nasceu em 1947, no dia 20 de julho, filho de Nemézio e Alaíde. Com apenas cinco anos, seu pai começou a lhe ensinar música, utilizando o método de solfejo do autor Alexis de Garaudé. Já aos 10 anos, tocava clarinete na banda da cidade. Menino curioso e criativo, usava cachos de banana para brincar de saxofone. Sempre muito ligado à cultura, participava de grupos de folclore e chegou a formar um grupo de pífanos (REVISTA DE PIRANHAS, 2014 p. 4).

Participou de bandas de bailes, na época em Maceió dividiu palcos com os músicos Djavan, Beto Batera, Canhoto da Paraíba, Carlos Bala, Luiz Gonzaga, Cauby Peixoto e Reginaldo Rossi, Nordestinados, Banda de Pau e Corda e Canhoto da Paraíba. Músico luthier, compositor, arranjador e produtor musical, trabalhou em diversas gravações e foi apresentado à Ariano Suassuna e convidado para executar os projetos Armorial e Quinteto no Recife.

[...] Egildo nunca tinha pego numa flauta, Egildo não tinha flauta e Egildo não sabia o que era Armorial. Agora ele tinha uma bagagem musical muito forte, porque ele foi menino em Piranhas e, ele não só tocava com as bandas de música clarinete, como ele tocava pífano com as bandas de pífanos e aprendeu a fabricar e depois ele desenvolveu uma técnica de fabricação de pífanos que é uma coisa que entrou para história a contribuição dele para história do pífano é definitiva. Ele tinha essa formação, formação de músico popular muito grande, mas na verdade ele tocava em conjuntos de bares a noite em Maceió (MADUREIRA, 2019).

Em 1972, Egildo Vieira gravou sua primeira obra musical no disco "Do ao Romance ao Galope" do quinteto Armorial, tocando flauta e pífano. Tornou-se professor do Curso de Extensão em Música do departamento do Centro de Artes e Comunicações (CAC) da Universidade Federal de Pernambuco - UFPE. Além disso, fundou os grupos: Pernambucano de Choro, Orquestra de Pau e Corda, Bloco da Saudade, Orurubá e Som da Terra.

Durante o ano de 2008, realizou turnê por todo Brasil, apresentando suas músicas pelo Sonora Brasil, projeto criado e coordenado pelo Serviço Social do Comércio - SESC. Retornou para sua cidade natal em 2009, fundou e assumiu o cargo de diretor do Conservatório de Música de Piranhas. Abrilhantava os eventos como maestro da banda da cidade e com seu recente Grupo de Música Armorial de Piranhas - GMAP.

\section{Repertório}

Fazem parte da pesquisa as seguintes composições:

- Deixa o Breque pra mim - Altamiro Carrilho - Choro-samba (1957)

- Bebê - Hermeto Pascoal - Baião (1976)

- Lamento do São Francisco - Egildo Vieira - Suíte: novena, cabocolinho (toque de guerra), galope, romance e lamento (2003)

- Frevo Poeirado - Egildo Vieira - Frevo (1997)

- Forró de Salú - Egildo Vieira - Forró (2004) 


\section{Categorização}

Classificação usada para amostra diversificada das células rítmicas dos gêneros e subgêneros de ritmos de danças populares

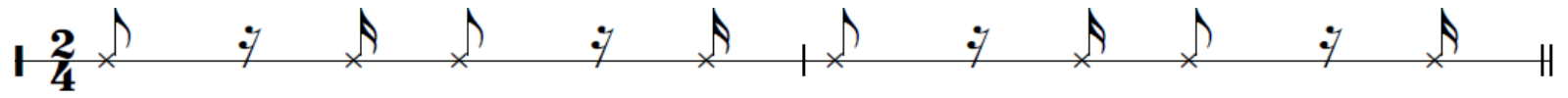

Figura 3 - Samba

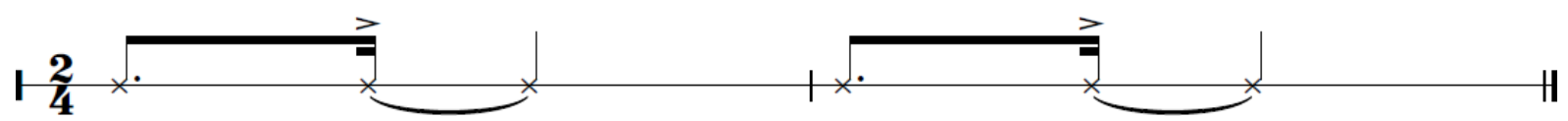

Figura 4 - Baião

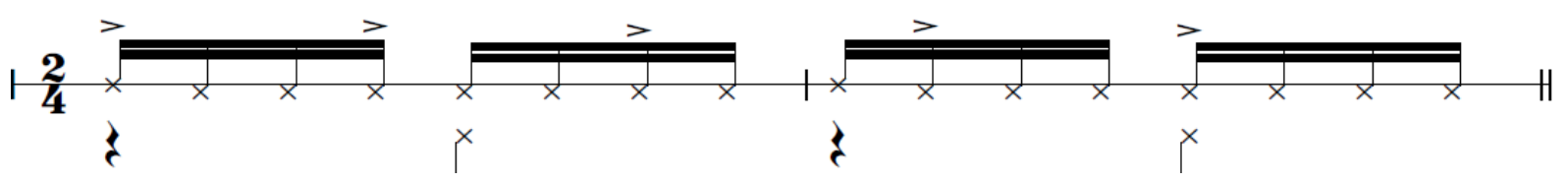

Figura 5 - Frevo de rua

Música Armorial $\left\{\right.$ caboclinho $^{17}$ novena $^{18}$, galope $^{19}$, romance ${ }^{20}$, lamento ${ }^{21}$. Segundo Nascimento (2015) são células rítmicas compostas através das formas poéticas e religiosas das manifestações culturais do Sertão de Alagoas - AL.

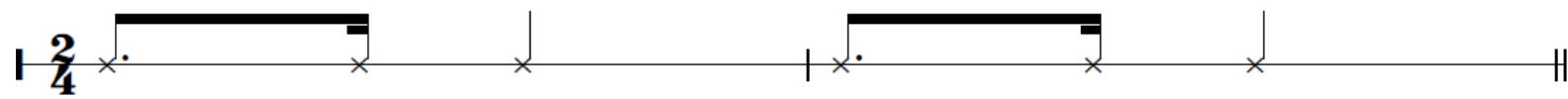

Figura 6 - Caboclinho - Toque de Guerra

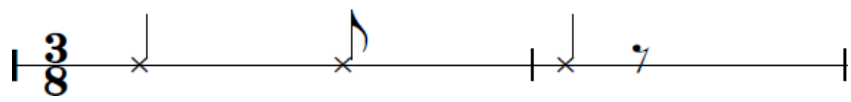

Figura 7 - Novena



Figura 8 - Galope

\footnotetext{
${ }^{17}$ Agremiação popular.

${ }^{18}$ Reza cantada em manifestação religiosa durante noves dias do mês de maio.

${ }^{19}$ Forma poética literária da cantoria originada pelos cantadores de viola, trata-se de um diálogo cantado visando impressionar e dominar o adversário.

${ }^{20}$ Forma poética literária de origem ibérica é uma narrativa cantada com acompanhamentos instrumentais.

${ }^{21}$ Gênero literário e musical que foi muito difundido na Idade Média, tanto em latim como em língua vernácula.
} 


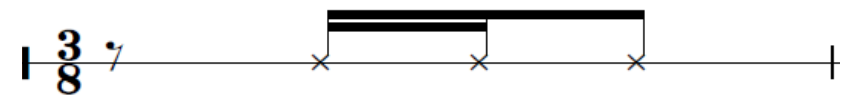

Figura 9 - Romance

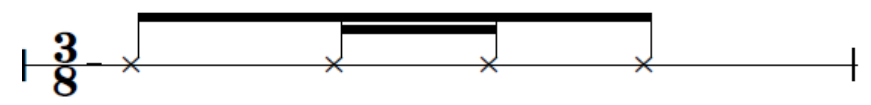

Figura 10 - Lamento

\section{Sinopse das Composições}

As composições selecionadas tiveram influência das manifestações culturais tanto do subúrbio quanto do sertão do Brasil. Nelas estão expostos sonoridades e modos encontrados desde o forró ${ }^{22}$ até os elementos rítmicos e sonoros do cabocolinho ${ }^{23}$, do frevo, do baião ${ }^{24} \mathrm{e} \mathrm{do} \mathrm{samba}^{25}$, antes considerados como folclore nacional.

\section{Altamiro Carrilho - Deixa O Breque Pra Mim (1957)}

"Samba de batucada, composto por causa das cinco horas de baile, não tinha mais o que tocar, esgotou o repertório, então começou a improvisar dando uma parada para cada músico do grupo improvisar, daí surgiu Deixe o breque pra mim" [..]. Texto informado pelo autor da obra.

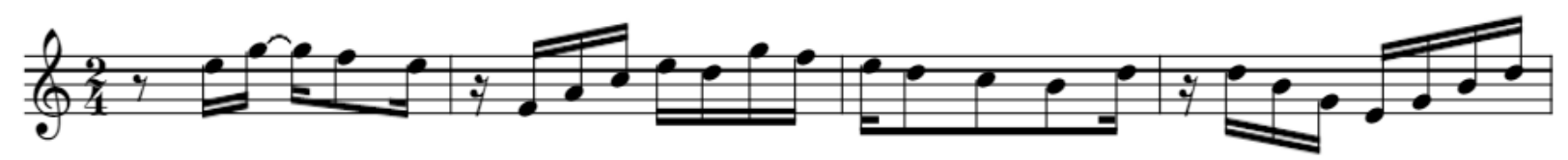

Figura 11 - Fragmentos melódicos da composição Deixe o breque pra mim (1957) e intervalo de 3ạ maior que caracteriza o modo Jônico da composição (MED, 1996. p. 166).

Hermeto Pascoal - Bebê (1976)

“Baião composto em homenagem ao nascimento do filho [...]”. Texto informado por Fábio Pascoal, filho e produtor de Hermeto Pascoal autor da obra.

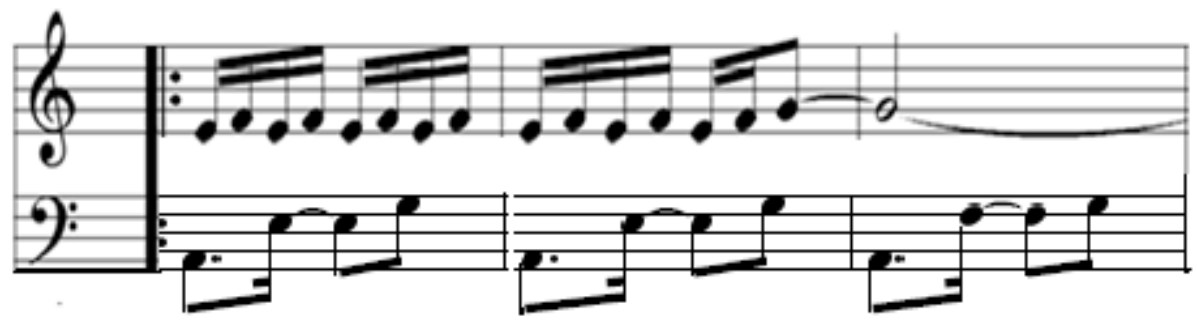

Figura 12 - Fragmentos melódicos da composição e intervalo de 3a menor que caracteriza o modo Eólio da composição (MED, 1996. p. 166).

\footnotetext{
${ }^{22}$ Manifestação cultural da região do Nordeste.

${ }^{23}$ Dança de agremiação carnavalesca de Pernambuco.

${ }^{24}$ Dança que faz parte dos festejos juninos do nordeste do Brasil.

${ }^{25}$ Dança oriunda dos terreiros do candomblé no Rio de Janeiro.
} 


\section{Egildo Vieira - Poeirado}

"Frevo composto no ano de 1997 através da inspiração do povo dançando frevo e, ao mesmo tempo, por causa dos passos subindo poeira no meio da multidão" [...] texto informado pelo autor da obra

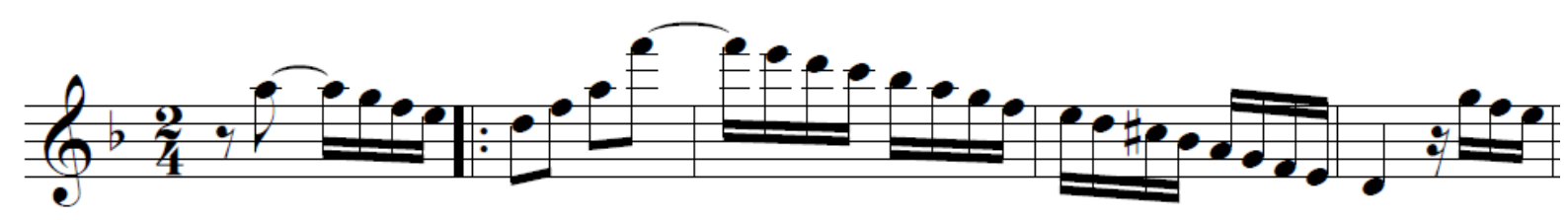

Figura 13 - Fragmentos melódicos da composição e intervalo de 3a menor que caracteriza o modo Eólio da composição, segundo (MED, 1996. p. 166).

\section{Egildo Vieira - Lamento do São Francisco}

"Música Armorial composta no ano de 2003. Durante uma visita a piranhas, Egildo avistou o Rio São Francisco muito seco na época da estiagem, o rio estava tão seco que mostrava as pedras à mostra que pareciam as costelas de fora[...]”. Texto informado pelo autor da obra.

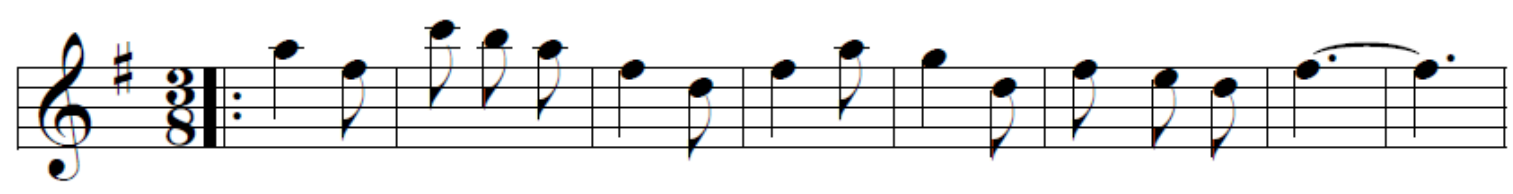

Figura 14 - Fragmentos melódicos e intervalo de 7ạ menor que caracteriza o modo Mixolídio na composição (MED, 1996. p. 166).

\section{Egildo Vieira - Forró de Salú}

"Baião composto no ano 2004 em homenagem ao forró da Casa da Rabeca do mestre Salustiano [...]". Texto informado pelo autor da obra.

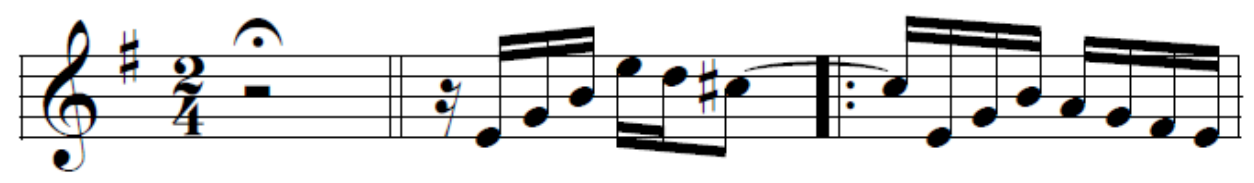

Figura 15 - Fragmentos melódicos e intervalo de 4ạ aumentada que caracteriza o modo Lídio da composição (MED, 1996. p. 166).

\section{Considerações Finais}

De acordo com foco central desde trabalho, apresentamos compositores que se tornaram destaques para literatura da "flauta transversal brasileira", expandiram suas formas composicionais, obras de diferentes vertentes dentro dos gêneros Popular e Erudito estimulando e influenciando novos compositores.

Dessa forma, refletirmos criticamente acerca dos processos tradicionais de ensino e aprendizagem da performance musical na música brasileira, sobretudo na música nordestina. Compreendendo os processos próprios, pessoais, métodos e resultados de pesquisa na área da performance musical.

Portanto, propomos desenvolver este artigo para mostrar o quanto é importante à pesquisa, o ensino $\mathrm{e}$ a prática musical que são aprendizagem que proporcionam articulações dos saberes visando construtivamente a qualidade musical do instrumentista, possibilitando o embasamento teórico e técnico para construção de conceitos, transformando em experiências significativas para o currículo do profissional. 


\section{Referências}

ANJOS, Alexandre Johnson dos. A gaita do caboclinhos e seus reflexos nas obras do repertorio compositores nacionais. Tese (doutorado em música). Rio de janeiro: Universidade do Rio de Janeiro, 2007.

BARREIRAS, Júlio. Educação popular e conscientização. 1a ed. Petrópolis: Vozes, 1980.

CHEDIAK, Almir. Harmonia \& Improvisação. $2^{\text {a }}$ ed. 70 músicas analisadas: violão guitarra, baixo e teclado / São Paulo: Irmãos Vitale, 2009.

DALDEGAN, Valentina; Costa, Raul. Pattapios: Coletânea comemorativa aos 20 anos da Associação Brasileira de Flautistas. Curitiba: Antigoa Typographia ABRAF, 2014.

DEIXE O BREQUE PRA MIM. Disponível em http://www.hermetopascoal.com.br/. Acesso em 16/08/2020

DIAS, Odette Ernest. Matheus André Rechert: um flautista Belga na corte real do Rio janeiro Brasilia: editora UNB, 1990.

DIAS, Andréa Ernest. A expressão da flauta popular brasileira: uma escola de interpretação. Dissertação (mestrado em música) Rio de Janeiro: Universidade Federal do Rio de Janeiro, 1996.

DINIZ, André. Almanaque do choro: a história do chorinho, o que ouvir, o que ler, onde curtir. $1^{\text {a }}$ ed. Rio de Janeiro: Jorge Zahar, 2003.

NASCIMENTO, Egildo Vieira do. Entrevista de Leonardo Araujo da Silva em 08 de Maio de 2015. Piranhas. Áudio. Conservatório de Música de Piranhas

COSTA, Fabio Pascoal da. Entrevista de Leonardo Araujo da Silva em 10 de Janeiro de 2016. Recife. Texto. Rede Sociais

GUERRA-PEIXE, Cesar: Biografia de Cesar Guerra-Peixe. Disponível em: http://www.guerrapeixe.com/. Acesso em 07/11/2019.

MARIZ, Vasco. História da música no Brasil. 2ª ed. - Rio de Janeiro: Civilização Brasileira, 1983.

MADUREIRA, Antônio. Entrevista de Leonardo Araujo da Silva em 11 de maio de 2019. Recife. Áudio. Recife.

MACIEL, Jarbas. Entrevista de Leonardo Araujo da Silva em 08 de agosto de 2014. Recife. Áudio. Recife.

MED, Bohumil. Teoria da música. 4a ed. Brasília: Musimed,1996.

GUERRA-PEIXE, Cesar. A Inúbia do cabocolinho: para flauta e piano, violino e piano, clarineta e piano: música brasileira para flauta. São Paulo: Irmãos Vitale, 1997.

REVISTA MÚSICA, São Paulo, 5v, n. 1:33 - 47 maio 1994. Disponível em: http://www.revistas.usp.br/ revistamusica/article/viewFile/55070/58712. Acesso em: 10/09/2015.

REVISTA DE PIRANHAS: Maestro Egildo Vieira. 1ª ed. Piranhas: VSvogashift, 2014.

RONAI, Laura. Em busca de um mundo perdido: métodos de flauta do barroco ao século XX. $1^{\text {a }}$ ed. Rio de Janeiro: Topbooks, 2008.

SANTOS, Idellete Muzart Fonseca dos. Em demanda da poética popular: Ariano Suassuna e o Movimento Armorial - 2º edição. Campinas: Editora da Unicamp, 2009. 
SEVERIANO, Jairo. Uma história da música popular brasileira. 4ª ed. São Paulo: Editora 34, 2017.

STEVENS, John. Grove Music Online. 2001. Oxford University. Disponível em: https://www.oxfordmusiconline.com/grovemusic/view/10.1093/gmo/9781561592630.001.0001/omo-9781561592630-e-0000021905. Acesso em: 3 Set. 2020.

SCHAFER, R. Murray. A afinação do mundo: uma exploração pioneira pela história passada e pelo atual estado do mais negligenciado aspecto do nosso ambiente. Tradução brasileira. São Paulo: Fundação Editora da UNESP, 1997.

TAFFANEL, Paul e Gauber, Phillipe. Méthodo complete de flute. Paris: Alphonse Leduc, 1923.

TINHORÂO, José Ramos. Pequena história da música popular segundo seus gêneros. São Paulo $7^{\mathrm{a}}$ edição: Editora 34, 2013.

VILLAÇA, Edmiriam Módolo. O Menino Sinhô, vida e música de Hermeto Pascoal para crianças. Dissertação de (mestrado em música). Salvador, Universidade Federal da Bahia, 2005.

WOLTZENLOGEL, Celso Porta. Método Ilustrado de Flauta. 1 aed. São Paulo: Irmãos Vitale, 1984.

WONTZENLOGEL, Celso Porta. Entrevista de Leonardo Araujo da Silva em 08 de agosto de 2020. Recife. Áudio. Redes Sociais.

Recebido em 29/10/2020

Aceito em 23/11/2020 
